\title{
CORRECTION
}

View Article Online

View Journal I View Issue

W) Check for updates

Cite this: RSC Adv., 2021, 11, 17487

DOI: $10.1039 / \mathrm{d} 1 \mathrm{ra90111g}$

rsc.li/rsc-advances

\section{Correction: Exploration of the cofactor specificity of wild-type phosphite dehydrogenase and its mutant using molecular dynamics simulations}

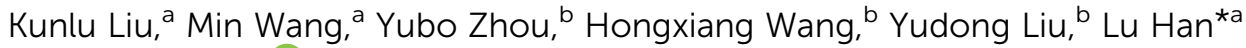 \\ and Weiwei Han (iD)*a \\ Correction for 'Exploration of the cofactor specificity of wild-type phosphite dehydrogenase and its mutant \\ using molecular dynamics simulations' by Kunlu Liu et al., RSC Adv., 2021, 11, 14527-14533, DOI: 10.1039/ \\ D1RA00221J.
}

The authors regret that an incorrect grant number was shown in the acknowledgements section of the published article. The corrected section should read:

This work was supported by the National Natural Science Foundation of China [31870201] and the Overseas Cooperation Project of Jilin Province [20200801069GH]. This work was performed at the High Performance Computing Center of Jilin University.

The Royal Society of Chemistry apologises for these errors and any consequent inconvenience to authors and readers. 